\title{
Stroke-mimics in stroke-units. Evaluation after changes imposed by randomized trials
}

\author{
Imitadores de AVC em unidades de AVC. Avaliação após alterações impostas por ensaios \\ randomizados
}

\author{
Héloïse IFERGAN', Aymeric AMELOT², Mohammad ISMAIL', Marie GAUDRON', Jean-Philippe COTTIER', \\ Ana Paula NARATA
}

\begin{abstract}
A larger therapeutic window for stroke treatment requires a significant change in the organization of emergency services, avoiding the increase in number of imaging exams and indirectly the time to treatment. Objective: To highlight the relation between faster clinical evaluation and stroke over-suspicion and consequently excessive imaging acquisition. To identify predictors of ischemic stroke and stroke mimics (SM), aiming for better patient selection for comprehensive neuroimaging and reperfusion therapies. Methods: Retrospective, cohort, observational, single-center study that reviewed all consecutive files of patients presenting with acute neurological symptoms who underwent CT scan or MRI from July 1, 2016 to July 1, 2017. Results: 736 patient files were reviewed. 385 patients (52.3\%) presented with confirmed acute ischemic infarct, 93 (12.6\%) had another brain lesion mimicking acute ischemia, and 258 (35.1\%) had normal imaging. Acute stroke was more frequent in elderly patients with atrial fibrillation, arterial hypertension, or dysarthria or right motor impairment. Stroke mimic was associated with female patients with low vascular risk factors, low NIHSS, and patients with decreased level of consciousness or symptoms suggestive of posterior circulation. Discussion: $47.7 \%$ of all patients seen at the stroke unit did not have acute stroke lesions. Clinical assessment data have been used to provide indicators of acute stroke and stroke mimic patients, and symptoms corresponding to acute stroke and stroke mimic seem to be similar in the literature. Conclusion: Considering that the number of patients admitted for stroke treatment will increase even further with a larger therapeutic window for mechanical thrombectomy and for thrombolysis, a diagnostic decision-making algorithm for stroke patients is required in order to reinforce the suspicion of stroke indicating an urgent MRI.
\end{abstract}

Keywords: stroke; stroke mimic; thrombectomy; thrombolysis.

RESUMO

Uma janela terapêutica maior para o tratamento do AVC exige uma mudança significativa na organização dos serviços de emergência, para evitar o aumento do número de exames de imagem e indiretamente o tempo de tratamento. Objetivo: destacar a relação entre avaliação clínica mais rápida e suspeita de acidente vascular cerebral e, consequentemente, aquisição de imagem excessiva, e identificar preditores de acidente vascular cerebral isquêmico e imitações de acidente vascular cerebral (SM), visando uma melhor seleção de pacientes para terapias abrangentes de neuroimagem e reperfusão. Métodos: estudo observacional de coorte retrospectivo, em centro único, que revisou todos os arquivos consecutivos de pacientes com sintomas neurológicos agudos submetidos à tomografia computadorizada ou ressonância magnética de 1 de julho de 2016 a 1 de julho de 2017. Resultados: Foram revisados 736 prontuários. 385 pacientes (52,3\%) apresentaram infarto isquêmico agudo confirmado, 93 (12,6\%) apresentaram outra lesão cerebral imitando isquemia aguda e 258 (35,1\%) apresentaram imagem normal. O AVC agudo foi mais frequente em pacientes idosos com fibrilação atrial, hipertensão arterial, ou disartria ou comprometimento motor direito. A imitação de acidente vascular cerebral foi associada a pacientes do sexo feminino com baixos fatores de risco vascular, NIHSS baixo e pacientes com diminuição do nível de consciência ou sintomas sugestivos de circulação posterior. Discussão: 47,7\% de todos os pacientes atendidos na unidade de AVC não apresentaram lesões agudas de AVC. Conclusão: Considerando que o número de pacientes admitidos para tratamento de AVC aumentará ainda mais com uma janela terapêutica maior para trombectomia e trombólise IV, é necessário um algoritmo de tomada de decisão diagnóstica para pacientes com AVC, a fim de reforçar a suspeita de AVC indicando uma imagem cerebral urgente.

Palavras-chave: acidente vascular cerebral; imitação de acidente vascular cerebral; trombectomia; trombólise.

\footnotetext{
'Service de neuroradiologie diagnostique et interventionnelle, Centre Hospitalier Régional et Universitaire de Tours, France.

${ }^{2}$ Service de neurochirurgie, Centre Hospitalier Régional et Universitaire de Tours, France.

${ }^{3}$ Service de neurologie vasculaire, Centre Hospitalier Régional et Universitaire de Tours, France.

Aymeric AMELOT (iD) https://orcid.org/0000-0003-3659-291X; Mohammad ISMAIL (iD) https://orcid.org/0000-0002-1455-1482; Jean-Philippe COTTIER (iD) https://orcid.org/0000-0003-0618-4026; Ana Paula NARATA (iD) https://orcid.org/0000-0001-5658-1439

Correspondence: Héloïse Ifergan; Department of Radiology and Neuroradiology University Hospital of Tours; 2 Boulevard Tonnellé, 37044 Tours, France; E-mail:ifergan.heloise@hotmail.fr

Conflict of interest: There is no conflict of interest to declare.
}

Received on April 04, 2019; Received in its final form on August 26, 2019; Accepted on September 18, 2019. 
A larger therapeutic window for stroke treatment requires a significant change in the organization of emergency services. Initially, most of the patients included in stroke treatment protocols were selected by symptom onset up to 4.5 hours for IV tissue plasminogen activator (IV tPA) therapy. Since the benefit of mechanical thrombectomy and the extension of indication of thrombolysis for patients with therapeutic window larger than 4.5 hours were determined, more patients were accepted in the emergency services to undergo imaging exams ${ }^{1,2}$.

Recently, selection has been based on imaging findings associated to clinical evaluation, rather than symptom onset time, to indicate which patients could benefit from IV tPA and endovascular arterial recanalization.

Imaging tools are used in order to determine a mismatch area when infarct lesion and neurological impairment do not overlap, at extended time windows, i.e., $>4.5$ and $>6 \mathrm{~h}$ for intravenous thrombolysis (IVT) and mechanical thrombectomy (MT) in large vessel occlusion patients, respectively.

The DAWN trial (Diffusion-Weighted Imaging or Computerized Tomography Perfusion Assessment With Clinical Mismatch in the Triage of Wake Up and Late Presenting Strokes Undergoing Neurointervention With Trevo $)^{2,3}$ defines mismatch as taking into consideration severity of the clinical deficit, infarct volume based on computed tomography (CT-scan), or magnetic resonance imaging (MRI) using diffusion weight imaging (MRI-DWI) to distinguish penumbra area from necrotic parenchyma, up to 24 hours from the symptom onset ${ }^{4-6}$.

Among the independent variables that might affect clinical evolution after stroke treatment, the time between onset of symptoms and treatment administration remains an essential factor, which may result in less time for managing diagnostic formulation ${ }^{7,8}$. Nevertheless, reducing the time of clinical assessment and extending time window for stroke treatment can result in an increase in imaging exams.

Stroke mimic is defined as a non-vascular disease with acute neurological deficits similar to stroke and represents 2 to $30 \%$ of suspected stroke cases ${ }^{9-12}$. A larger therapeutic window for stroke treatment considerably increased the number of imaging exams in emergency services and indirectly increased the interval between patient arrival and treatment, known as "door to treatment time". Although IV tPA administered to stroke mimic seems to have low complication rates, unnecessary IV tPA administration presents risks and costs that could be avoided.

The importance of achieving early recognition of stroke mimic is to avoid unnecessary imaging analysis, give priority to patients who are more likely to have acute ischemia, and prevent stroke treatment in patients without arterial occlusion $^{12-18}$.

The objective of this study was to create a direct link between faster clinical evaluation and stroke over-suspicion, which results in excessive imaging acquisition, and to identify predictors of ischemic stroke and stroke mimics, for better patient selection for comprehensive neuroimaging and reperfusion therapies.

The number of patients arriving was evaluated as "stroke alerts". The number of stroke mimicking patients were quantified and stroke mimics and symptoms were correlated in order to optimize primary selection and spot a correlation between symptoms and therapeutic decision as a predictive factor to anticipate possible treatment and early stroke team warn.

\section{METHODS}

\section{Patient selection and clinical data assessment}

The study was a retrospective, cohort, observational, single-center study. All consecutive records of patients who had undergone computerized tomography (Scanner GE MEDICAL Discovery CT750HD. Non-contrast: slice thickness $1.25 \mathrm{~mm}-100 \mathrm{kV}-250 \mathrm{~mA}$, CTA arch-to-vertex: slice thickness $0.625 \mathrm{~mm}-120 \mathrm{kV}-520 \mathrm{~mA}-50 \mathrm{cc}$ injected at 4-7cc/s with a subsequent $40 \mathrm{~mL}$ saline chaser -, and dynamic first pass perfusion CT: $45 c c$ iodinated contrast agent, injected at $4 \mathrm{cc} / \mathrm{s}$ ) or magnetic resonance imaging, with or without perfusion - no arterial spin labeling (ASL) was performed - (MRI Siemens Verio 3T. Axials diffusion: slice thickness $4 \mathrm{~mm}$ - interslice gap $0.4 \mathrm{~mm}$ - repetition time TR 5600 - echo time TE 62 - flip angle 180 - matrix $144 \times 180$ - field of view $230 \times 230$, fluid-attenuation-inversion recovery FLAIR: slice thickness $5 \mathrm{~mm}$ - interslice gap $1.5 \mathrm{~mm}$ - TR 9000 - TE 123 - flip angle 150 - matrix $205 \times 256$ - inversion time 2500 - FOV $230 \times 230$-, susceptibility weighted imaging SWI: slice thickness $2 \mathrm{~mm}$ - interslice gap 0.4 mm - TR 36 - TE 18 - flip angle 15 - matrix $192 \times 236$ - FOV $265 \times 199$-, time offlight TOF: slice thickness 0.7 - interslice gap 4.2 mm - TR 20 - TE 3.6 - flip angle 18 - matrix $220 \times 256$ - FOV $180 \times 163$, and perfusion weighted imaging if it were necessary: slice thickness $4 \mathrm{~mm}$ - interslice gap $1 \mathrm{~mm}$ - TR 1750 - TE 29 flip angle 90 - matrix $128 \times 128$ - FOV $245 \times 245$ - intravenous bolus injection of gadolinium with MultiHance, Bracco, Milan, Italy and dynamic image acquisition started 35-40 seconds before the contrast agent entered the brain and ended after a few recirculation passes of the contrast agent, with the first pass approximately in the middle of the acquisition, post-processing workstation: Syngo.via, Siemens Healthcare, Forchheim, Germany) in the context of stroke alert in the institution from July 1, 2016 to July 1, 2017 were reviewed. Two neuroradiologists have reviewed all data. All patients were included without any exclusion criteria. Institutional review board approval was obtained without requiring consent for retrospective and anonymous data collection.

Epidemiological, clinical, and imaging data were analyzed. Neurological symptoms, past medical history, physical examination, and treatment provided were accessed through local computer patient-data records. Imaging data 
was reviewed using Picture Archiving and Communication Systems (PACS).

\section{Local admission protocol}

A neurologist receives all calls concerning suspected stroke and decides which patients need to reach the hospital immediately (stroke unit) and be examined by MRI or CT scan. Within the hospital, the patients are briefly examined in order to obtain the National Institute of Health Stroke Scale (NIHSS) and questioned, if possible, before undergoing imaging. Additional information may be obtained by questioning emergency rescue service, personal doctor, and family.

MRI is the first-choice local imaging tool to study stroke patients and only patients with a contra-indication to MRI (pacemaker or suspicion of metal implants in general, major motor agitation) are studied by CT-scan.

\section{Stroke and stroke mimic}

Patients were retrospectively classified into three groups based on imaging data. Group I: confirmed stroke with evidence of acute ischemia correlated to clinical presentation; Group II: stroke mimic without acute ischemia, but with other brain lesion that may explain neurological symptoms; Group III: stroke mimic without any brain lesion that may explain clinical presentation, therefore final diagnosis will be achieved based on clinical analysis and additional exams.

All patients with confirmed stroke had been considered for suitable treatment (thrombolysis only, thrombolysis + thrombectomy or thrombectomy only, or no treatment).

Based upon imaging analysis only, positive findings consisted of acute ischemic lesions, intra-parenchymal hematoma, subdural hematoma, subarachnoid hemorrhage, glial tumors, secondary brain tumors, other brain tumors, multiple sclerosis, and others. Negative findings associated with a clear clinical presentation (part of Group III) included seizure and migraine if there were no lesions visible on perfusion, transient ischemic attacks (TIA), and somatoform disorders.

\section{Statistical analysis}

Associations between variables were analyzed by Fisher's exact test or chi-square test. The distribution of categorical variables was described by frequencies and percentages, continuous and normally distributed variables by means and standard deviations (SD), or range. Predictive factors for stroke or mimic were tested by univariate statistics using ANOVA and chi-square or Fisher exact tests, as appropriate. Depending on the number of pairwise comparisons of interest, type 1 error was adjusted using the Bonferroni multiple comparison adjustment. For example, $\alpha$ level of 0.05 divided by 17 comparisons yielded an adjusted $\alpha$ of 0.003 ; thus, statistical significance level was set at $p=0.003$. All variables with a significant association in the univariate analyses after adjustment were entered into a multiple logistic regression model using backward elimination procedures to analyze potential predictors of stroke or mimic. A forest plot was constructed based on odds ratio (OD) determined using a logistic regression model. Analyses were performed using Microsoft Excel (version 97 SR-2), Statistical Package for the Social Sciences (version 11.0.0), and Confidence Interval Analysis software (Martin J. Gardner and British Medical Journal, 1989).

\section{RESULTS}

\section{Baseline characteristics and clinical presentation}

A sample of 736 consecutive patients was included, covering the period from July $1^{\text {st }}, 2016$ to July $1^{\text {st }}, 2017$. The mean age was 65.9 years-old (minimum 9, maximum 96), with a slightly larger number of males (49.3\% were female, p-value 0.026). Median NIHSS was 4 (0 to 27). Arterial hypertension was present in $52.2 \%$ of patients, dyslipidemia in $29.7 \%$, and there was history of stroke, TIA, myocardial infarction, or angina pectoris in $24.7 \%$. Lateralized motor impairment was present in $79 \%$ of patients, followed by aphasia in $20.9 \%$ of patients, and dysarthria in $12.8 \%$. General epidemiological characteristics and clinical presentation are reported in Table 1.

\section{Imaging analysis}

Only four $(0.5 \%)$ patients from 736 included in this study were examined using a CT scan. Three of those patients were confirmed as acute ischemia (Group I), and one as multiple sclerosis after additional MRI. 385 patients (52.3\%) presented confirmed acute ischemia (Group I), 93 (12.6\%) had other brain lesion mimicking acute ischemia (Group II), and 258 $(35.1 \%)$ had normal brain imaging (Group III). Clinical presentation and medical history were analyzed separately considering stroke patients (Group I) and stroke mimic patients (Groups II and III) (Figure 1).

In Group II, the most common brain lesion was intraparenchymal hematoma, found in 54 patients $(7.3 \%)$, followed by migraine with aura $(0.8 \%)$, glial lesion $(0.7 \%)$, other tumor $(0.5 \%)$, metastasis $(0.7 \%)$, seizure $(0.4 \%)$, sub-dural hematoma, subarachnoid hemorrhage, and multiple sclerosis, all with $0.4 \%$ prevalence. Results of stroke mimic positive imaging findings are reported in Table 2.

Regarding Group III, 79 patients (10.7\%) had no clinical diagnosis, 48 patients (6.5\%) were TIAs, 42 (5.7\%) somatoform disorders, 27 (3.7\%) migraine with aura, 23 (3.1\%) seizure, 19 (2.6\%) peripheral etiology, $4(0.5 \%)$ alcohol intoxication, 3 $(0.4 \%)$ fluid and electrolyte disturb, 2 (0.3\%) hypoglycemia, and $2(0.3 \%)$ iatrogenic cause. Group III final diagnosis was based on physician expertise, complementary exams (electro-physiologic and biological exams), and follow-up (data collection started 6 months after the last patient was admitted in acute phase). Detailed results are reported in Table 3 (Figures 1, 2, 3 and 4). 
Table 1. Characteristics of stroke and stroke mimic population.

\begin{tabular}{|c|c|c|}
\hline & Stroke & Stroke mimic \\
\hline Baseline characteristics & $385(52.3 \%)$ & $351(47.7 \%)$ \\
\hline \multicolumn{3}{|l|}{ Demographic variables } \\
\hline Age mean years & 70.9 & 60 \\
\hline Female gender & $167(43.4 \%)$ & $196(55.8 \%)$ \\
\hline \multicolumn{3}{|l|}{ Risk factors } \\
\hline Arterial hypertension & $235(61.0 \%)$ & $150(42.7 \%)$ \\
\hline Atrial fibrillation & $50(13.0 \%)$ & $17(4.8 \%)$ \\
\hline Diabetes mellitus & $65(16.9 \%)$ & $47(13.4 \%)$ \\
\hline Hypercholesterolemia & $135(35.1 \%)$ & $84(23.9 \%)$ \\
\hline $\begin{array}{l}\text { Smoking (current or } \\
\text { stopped less than } 5 \\
\text { years) }\end{array}$ & $58(15,1 \%)$ & $58(16.5 \%)$ \\
\hline Overweight or obesity & $92(23.9 \%)$ & $66(18.8 \%)$ \\
\hline $\begin{array}{l}\text { Personal history of } \\
\text { stroke / TIA / angor / } \\
\text { myocardia infarcts }\end{array}$ & $104(27.0 \%)$ & $78(22.2 \%)$ \\
\hline $\begin{array}{l}\text { Familial history of stroke } \\
\text { / TIA / angor / myocardia } \\
\text { infarcts at young age }\end{array}$ & $12(3.1 \%)$ & $10(2.8 \%)$ \\
\hline History of ictus & $0(0.0 \%)$ & $1(0.3 \%)$ \\
\hline History of migraine & $13(3.4 \%)$ & $25(7.1 \%)$ \\
\hline \multicolumn{3}{|l|}{ Stroke severity: NIHSS } \\
\hline NIHSS 1-5 & $174(45.2 \%)$ & $159(45.3 \%)$ \\
\hline NIHSS 6-15 & $101(26.2 \%)$ & $50(14.2 \%)$ \\
\hline NIHSS 16-20 & $43(11.2 \%)$ & $14(4.0 \%)$ \\
\hline$N I H S S>21$ & $26(6.8 \%)$ & $7(2.0 \%)$ \\
\hline Median NIHSS & 5 & 2 \\
\hline \multicolumn{3}{|l|}{ Clinical syndrome } \\
\hline Seizure & $3(0.8 \%)$ & $3(0.9 \%)$ \\
\hline Cephalalgia & $15(3.9 \%)$ & $43(12.3 \%)$ \\
\hline Aphasia & $90(23.4 \%)$ & $64(18.2 \%)$ \\
\hline Dysarthria & $66(17.1 \%)$ & $28(8.0 \%)$ \\
\hline Ataxia & $26(6.8 \%)$ & $40(11.4 \%)$ \\
\hline $\begin{array}{l}\text { Right sensitive-motor } \\
\text { deficit }\end{array}$ & $170(44.2 \%)$ & $112(31.9 \%)$ \\
\hline $\begin{array}{l}\text { Left sensitive-motor } \\
\text { deficit }\end{array}$ & $157(40.8 \%)$ & $143(40.7 \%)$ \\
\hline $\begin{array}{l}\text { Decreased level of } \\
\text { consciousness }\end{array}$ & $6(1.6 \%)$ & $15(4.3 \%)$ \\
\hline "Other" & $28(7.3 \%)$ & $57(16.2 \%)$ \\
\hline Speech problem & $38(9.9 \%)$ & $36(10.3 \%)$ \\
\hline Imaging: CT-scan & $3(0.8 \%)$ & $1(0 \%)$ \\
\hline Imaging:MRI & $382(99,2 \%)$ & $350(99.7 \%)$ \\
\hline Treatment & $188(48.8 \%)$ & \\
\hline Thrombolysis & $151(39.2 \%)$ & \\
\hline Thrombectomy & $84(21.8 \%)$ & \\
\hline Both & $37(9.6 \%)$ & \\
\hline
\end{tabular}

NIHSS: National Institute of Health Stroke Scale;TIA:transient ischemic attacks.

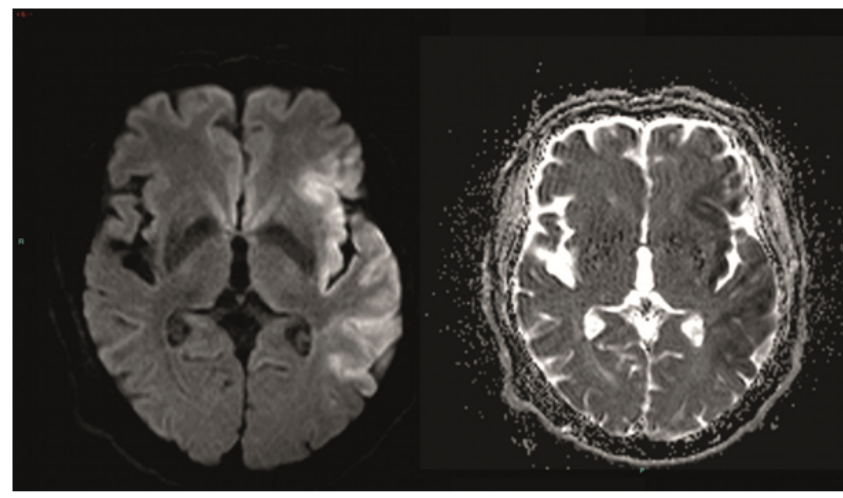

Figure 1. Acute ischemic lesion: pattern of restricted diffusion (hyperintensity in DWI with correspondant hypointensity in ADC).

Table 2. Stroke mimic positive imaging findings.

\begin{tabular}{|lc|}
\hline Condition & Frequency (\%) \\
\hline Intra-parenchymal hematoma & $54(7.3 \%)$ \\
\hline Other & $7(0.9 \%)$ \\
\hline Migraine with aura & $6(0.8 \%)$ \\
\hline Glial lesion & $5(0.7 \%)$ \\
\hline Another tumor & $4(0.5 \%)$ \\
\hline Metastasis & $5(0.7 \%)$ \\
\hline Seizure & $3(0.4 \%)$ \\
\hline Sub-dural hematoma & $3(0.4 \%)$ \\
\hline Sub-arachnoidal hematoma & $3(0.4 \%)$ \\
\hline Multiple sclerosis & $3(0.4 \%)$ \\
\hline
\end{tabular}

Other findings: 1 compressive arachnoidal cyst, 1 medullar ischemia, 2 internal carotid artery hypoperfusion, 1 posterior reversible encephalopathy syndrome (PRES), 1 mitochondrial myopathy, encephalopathy, lactic acidosis, and stroke (MELAS), 1 venous infarction, post-ictal MRI abnormalities, internal carotid artery hypoperfusion.

Table 3. Group III: final diagnosis achieved based on clinical analysis and supplementary exams.

\begin{tabular}{|lc|}
\hline Condition & Frequency (\%) \\
\hline No diagnosis at final & $79(10.7 \%)$ \\
\hline Transient ischemic attack & $48(6.5 \%)$ \\
\hline Somatoforms troubles & $42(5.7 \%)$ \\
\hline Migraine with aura & $27(3.7 \%)$ \\
\hline Seizure & $23(3.1 \%)$ \\
\hline Peripheral etiology & $19(2.6 \%)$ \\
\hline Other & $11(1.5 \%)$ \\
\hline Alcohol intoxication & $4(0.5 \%)$ \\
\hline Fluid and electrolyte disturb & $3(0.4 \%)$ \\
\hline latrogenic cause & $2(0.3 \%)$ \\
\hline Hypoglycemia & $2(0.3 \%)$ \\
\hline
\end{tabular}




\section{Treatment}

Eighty-four (11.3\%) patients had mechanical thrombectomy (37 patients, 5.0\%, thrombectomy only), 151 thrombolysis (20.3\%) (103, 13.9\%, thrombolysis only), and 47 (6.3\%) thrombectomy plus thrombolysis.

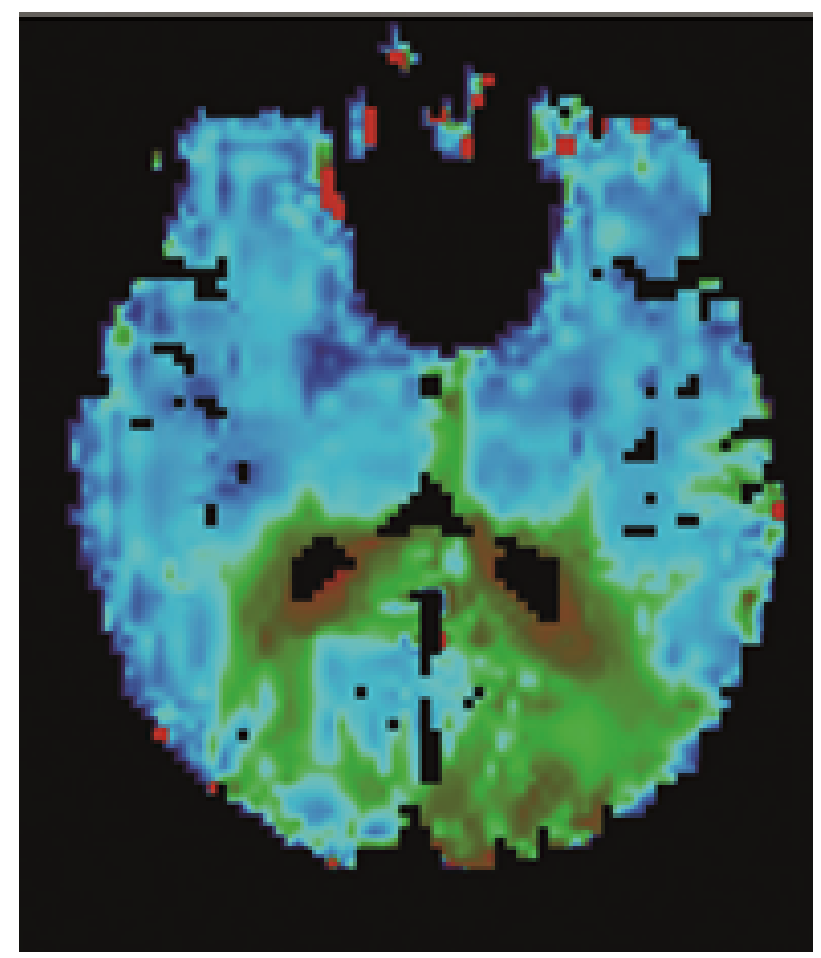

Figure 2. Migraine with aura at following headache phase: moderate increase of the time to peak (TTP) not limited to a specific vascular territory.

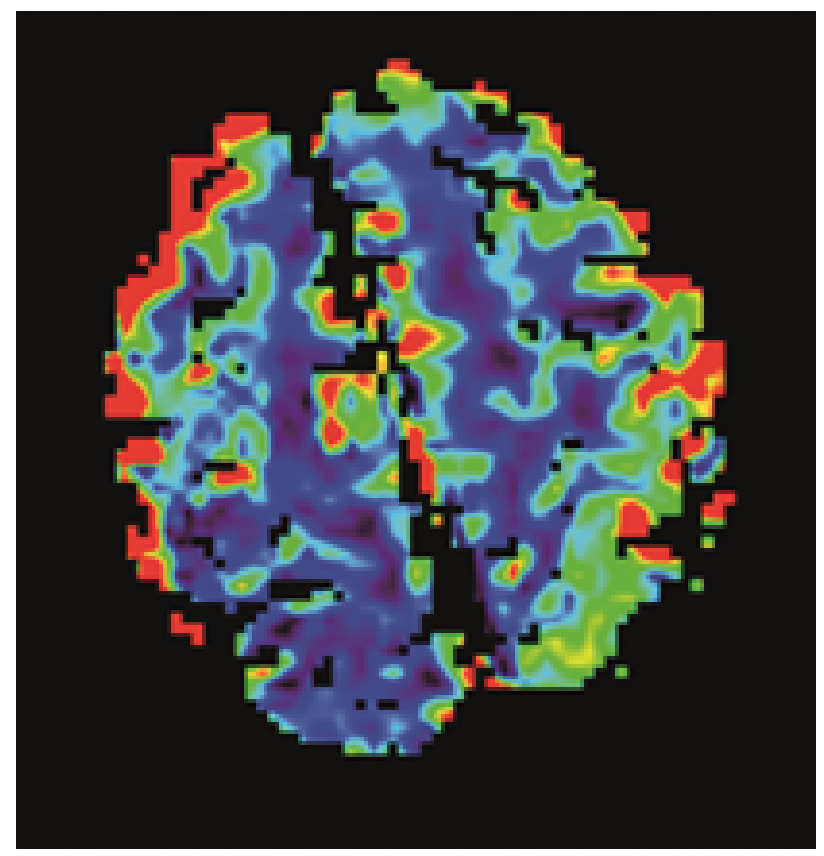

Figure 3. Post-ictal MRI perfusion abnormalities: localized hyperperfusion (RBV) in the cortical gray matter and subcortical white matter, with mild mass effects.

\section{Clinical assessment and statistical analysis in} acute stroke, stroke mimic groups and treatment

Uni and multivariate logistic regression showed a significant association of acute stroke and advanced age (mean age 70.9 years in stroke group, and 60 in stroke mimic group, OR: 1.32; $\mathrm{p}=0.004 ; 95 \% \mathrm{CI}$ [1.09-1.60]), atrial fibrillation (13.0\% in stroke group and $4.8 \%$ in stroke mimic group, OR 1.91; $\mathrm{p}=0.043$; 95\%CI 1.02-3.57), and arterial hypertension (61.0\% in stroke group, $42.7 \%$ in stroke mimic group, OR 2.46; $\mathrm{p}=0.024$; 95\%CI 1.18-3.61), dysarthria (17.1\% in stroke group and 8.0\% in stroke mimic group, OR 2.02; $\mathrm{p}=0.007$; 95\%CI 1.20-3.36), or right-sided deficit (44.2\% in stroke group, $31.9 \%$ in stroke mimic group, OR 1.47; $\mathrm{p}=0.025$; $95 \% \mathrm{CI} 0.51-1.99$ ) at the initial neurologic examination.

A significant association to stroke mimic was found among females (55.8\% in stroke mimic group, $43.4 \%$ in stroke group, OR 0.69; $\mathrm{p}=0.026$; 95\%CI 0.49-0.95), low vascular risk factors (OR 1.466; $\mathrm{p}=0.011$; 95\%CI 1.091-1.969), with low NIHSS score (NIHSS 1-5 OR 0.25; $\mathrm{p}<0.0001 ; 95 \%$ CI 0.15-0.40), with decreased level of consciousness ( $4.3 \%$ in stroke-mimic group, $1.6 \%$ in stroke group, OR 0.32; $\mathrm{p}=0.033 ; 95 \%$ CI 0.11-0.91), or symptoms resembling posterior circulation impairment (11.4\% in stroke mimic, and $6.8 \%$ in stroke group, OR 1.818; $\mathrm{p}=0.049$; 95\%CI 1.002-3.299) (Figure 5).

There was a significant association with starting IV tPA if the patient had right-sided deficit (OR 1.705; $\mathrm{p}=0.006$; 95\%CI 1.163-2.500) or arterial hypertension (OR 1.579; $\mathrm{p}=0.024$; 95\%CI 1.062-2.348). Thrombectomy patients with high NIHSS-score (>20) (OR 2.927; $\mathrm{p}=0.003$; 95\%CI 1.457-5.881), left deficit (OR 2.427; $\mathrm{p}=0.002$; 95\%CI 1.377-4.277), and aphasia (OR 2.482; $\mathrm{p}=0.004$; 95\%CI 1.330-4.633) seemed to be more treated by thrombectomy.

\section{DISCUSSION}

Stroke mimics were present in $47.7 \%$ of the patients examined in acute phase of suspected stroke.

Clinical assessment data have been used to provide indicators of acute stroke and stroke mimic patients. Comparing

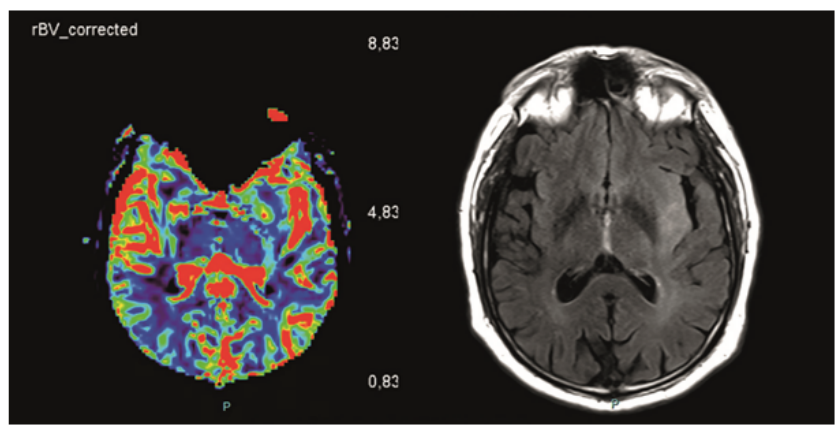

Figure 4. Left insular glioma in hypersignal FLAIR, axial sequence (left side), with elevation of the blood volume correlated to hyperperfusion (right side). 
the results of this study to the literature, common points concerning acute stroke are lateralized motor impairment, high NIHSS score, older patients, arterial hypertension, and atrial fibrillation. Stroke mimics were more common in younger female patients presenteding cognitive impairment, loss of consciousness, or posterior fossa symptoms (vertigo, ataxia), patients with low NIHSS or concomitant seizures. Statistical analysis showed that lateralized symptoms (right/left motor impairment) and high NIHSS scores are likely to signify proximal arterial occlusion ${ }^{8-11,13-16,18-27}$. Stroke mimicking conditions were virtually the same previously reported in literature ${ }^{11-29}$. The reported proportion, however, differs: seizure proportion is higher in literature studies than in this study, ranging from 16.7 to $26 \%^{11,28}$ TIA in $23 \%^{29}$, metabolic disorders in $18.9 \%^{30}$.

Literature review shows that stroke units can receive $2-38 \%$ of patients presenting stroke mimics and this number seems to be higher in larger stroke centers ${ }^{10,19-23,31}$.

The comparison between this study and literature is limited by the definition of SM in literature. Neurologists exclude TIA, venous infarction, and intracranial hemor-

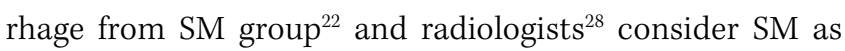
any lesion different from ischemic lesion or absence of any lesion in CT or MRI ${ }^{12,15,16,23,27}$.

In this study, by this second definition, it was found that $34.2 \%$ of patients presented stroke mimics (excluding vascular diseases mimicking acute arterial occlusion), which is slightly higher than a previous analysis performed in 2014 in the same stroke unit which identified $30 \%$ of stroke mimics $^{19}$. From January 1, 2014 to January 1, 2015, our institution received 352 patients for acute stroke assessment and 736 patients in this study from July 1, 2016 to July 1, 2017. Since thrombectomy and thrombolysis may be indicated in patients with a larger therapeutic window, we noticed a major increase in patients arriving for acute stroke treatment without significant change in pre-hospital evaluation. As previously mentioned, a greater number of patients could lead to shorter patient evaluation time, more imaging exams and patients without an acute ischemic lesion ${ }^{7,8}$.

We used MRI as the first choice to select stroke patients for treatment. The advantages include the precision to exclude stroke mimic patients and avoiding, for example, IV tPA without arterial occlusion ${ }^{22,25,27}$. However, complications rates after IV tPA in stroke mimic patients are very rare ${ }^{8,12-17}$.

Considering that the number of patients admitted in a stroke unit has the potential to further increase due to the enlargement of the therapeutic window and, on the other hand, that more patients who were previously not being screened are being considered for treatment, stroke units could use clinical algorithms based on clinical assessment data to give priority to those most likely to have an acute stroke. For institutions that use MRI as the first choice, CT-scan could be used for patients who have a high

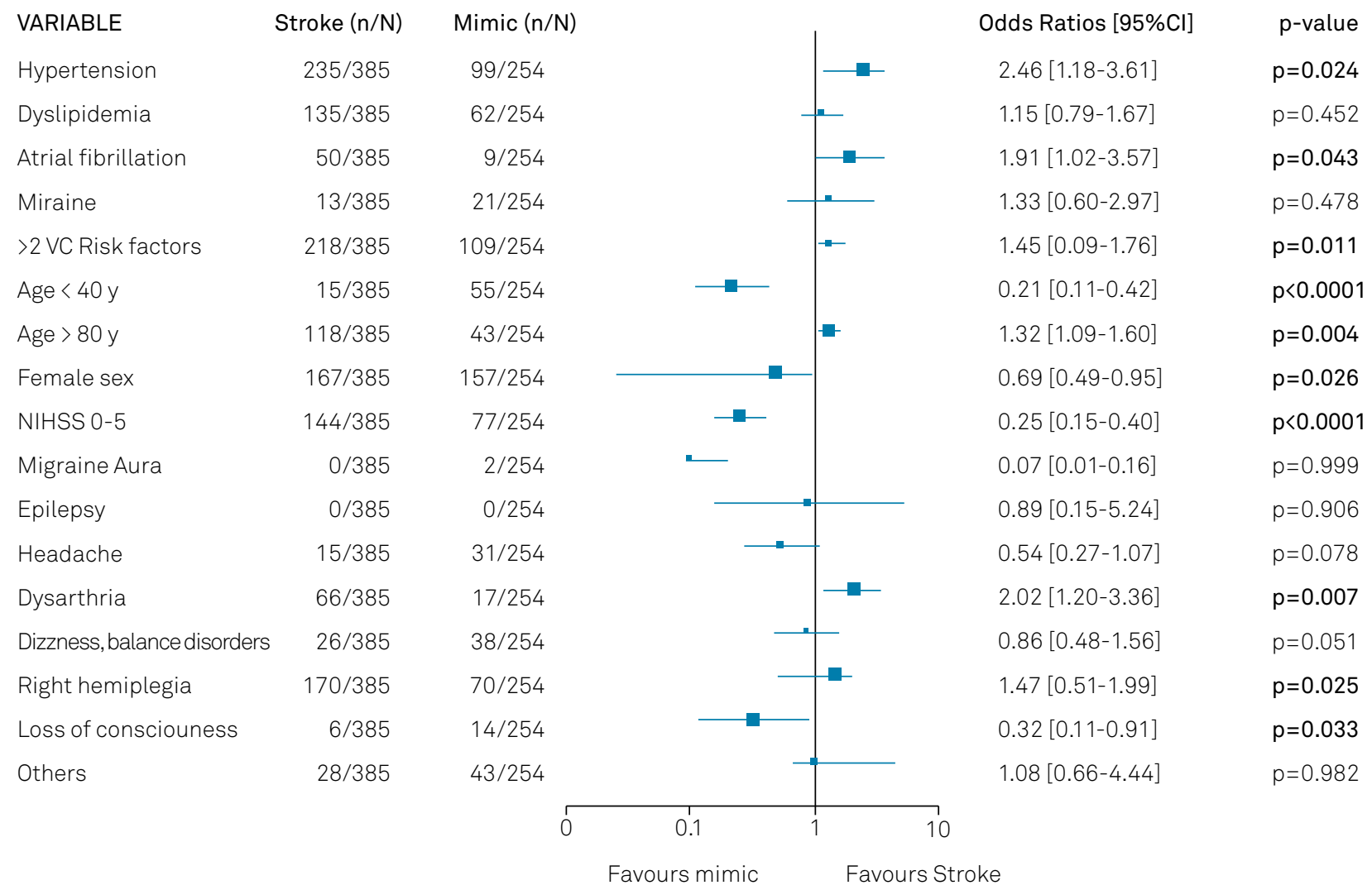

Figure 5. Logarithmic scale for Odds Ratios (ORs) with 95\% Cl initial clinical assessment that were statistically significant in predicting the final diagnosis from univariate analyses were analyzed with multivariate linear regression. An OR $>1$ predicts a stroke; <1 predicts a mimic. Statistically significant datas are in bold type, and with larger graphical marker. 
probability of stroke, limiting time between symptoms onset and thrombolysis, to determine whether there is a thrombus and its possible localization, eliminating hemorrhage and assessing collateral networks. Patients with a high probability of a stroke-mimic and patients needing further evidence to justify potential treatment in extended time window, based on initial clinical examination, should undergo MRI to determine the etiology of the neurological deficit and to avoid misdiagnosing a potential stroke. In our study, two patients with negative MRI were treated with IV thrombolysis, based on the hypothesis of infra-radiological stroke (stroke with normal MRI), with no related complications. The most important point is to use all imaging resources available to keep "door to treatment time" as low as possible. The technical resources in countries where we practice social medicine is one the verge of saturation, and those resources must be controlled.

Symptoms corresponding to acute stroke and stroke mimic seem to be similar in the literature, which suggest that a pre-imaging clinical algorithm could be applied to optimize triage of the patients, based on the clinical examination and past medical history, including cardio-vascular risk factors, NIHSS score, and symptoms onset timing.

Khan et al..$^{25}$ have already proposed an algorithm to help identify stroke mimic based on basic neurologic assessment such as age, stroke risk factors (hypertension, atrial fibrillation, diabetes mellitus type 2, hyperlipidemia), and other factors (migraines, epilepsy, psychiatric illness). Ideally, symptoms during the clinical examination should also be considered in order to have a pre-selection before indicating any imaging exam (NIHSS, dysarthria, or aphasia, left or right impairment).

This study has several limitations. Firstly, the database is monocentric, and it is a retrospective study. Furthermore, we had some cases of MRI negative ischemic strokes, which have been treated as stroke, and indexed as stroke-mimic, creating a potential bias. Finally, the definition of stroke-mimic is unclear in the literature, including in some cases vascular diseases mimicking acute arterial occlusion ${ }^{28}$, sometimes considering stroke-mimics only as non-neurovascular disease ${ }^{22}$, creating confusion in the terms, and causing a complexity of data comparison to that of literature.

The recent blooming of mechanical thrombectomy and also the potential to thrombolysis wake up strokes and stroke from 4.5 to $9 \mathrm{~h}$ lead to reconsider the patient's workflow for suspected acute ischemic stroke. Indeed, stroke units need to find solutions in order to be capable to offer the most efficient healthcare to patients who need resources to be emphasized. Randomized trials associated with local evaluations are required to adapt local resources and medical practice.

In conclusion, this study shows that there is a large proportion of stroke mimics among patients addressed for stroke suspicion. This could cause a problem of availability and/or delay for real stroke cases, and constitute a work overload for stroke centers, thus the selection of patients needs to be stricter, although the drawback of such might be delaying the imaging for some patients with stroke.

Acute stroke is associated with advanced age, atrial fibrillation, arterial hypertension, and dysarthria and right motor impairment at the initial neurologic examination. Stroke mimic is associated with female patients without vascular risk factors, patients with low NIHSS score, decreased conscious level, and symptoms suggesting impairment of posterior circulation.

Considering that the number of patients admitted for stroke treatment will increase even further with a larger therapeutic window for mechanical thrombectomy and for thrombolysis, a diagnostic decision-making algorithm for stroke patients is required in order to reinforce the suspicion of stroke indicating an urgent MRI.

\section{References}

1. Campbell BCV, Ma H, Ringleb PA, Parsons MW, Churilov L, Bendszus

$\mathrm{M}$, et al. Extending thrombolysis to 4.5-9 h and wake-up stroke using perfusion imaging: a systematic review and meta-analysis of individual patient data. Lancet. 2019 Jul;394(10193):139-47. https:// doi.org/10.1016/S0140-6736(19)31053-0

2. Goyal M, Menon BK, van Zwam WH, Dippel DW, Mitchell PJ, Demchuk AM, et al. Endovascular thrombectomy after large-vessel ischaemic stroke: a meta-analysis of individual patient data from five randomised trials. The Lancet. 2016 Apr;387(10029):1723-31. https:// doi.org/10.1016/S0140-6736(16)00163-X

3. Albers GW, Marks MP, Kemp S, Christensen S, Tsai JP, OrtegaGutierrez S, et al. Thrombectomy for stroke at 6 to 16 hours with selection by perfusion imaging. N Engl J Med. 2018 Feb;378(8):70818. https://doi.org/10.1056/NEJMoa1713973

4. Nogueira RG, Jadhav AP, Haussen DC, Bonafe A, Budzik RF, Bhuva P, et al. thrombectomy 6 to 24 hours after stroke with a mismatch between deficit and infarct. N Engl J Med. 2018 Jan;378(1):11-21. https://doi.org/10.1056/NEJMoa1706442
5. Baron CA, Kate M, Gioia L, Butcher K, Emery D, Budde M, et al. Reduction of diffusion-weighted imaging contrast of acute ischemic stroke at short diffusion times. Stroke. 2015 Aug;46(8):2136-41. https://doi.org/10.1161/STROKEAHA.115.008815

6. Wintermark M, Reichhart M, Cuisenaire O, Maeder P, Thiran JP, Schnyder P, et al. Comparison of admission perfusion computed tomography and qualitative diffusion- and perfusionweighted magnetic resonance imaging in acute stroke patients. Stroke. 2002 Aug;33(8):2025-31. https://doi.org/10.1161/01. str.0000023579.61630.ac

7. Haute Autorité de Santé - Accident vasculaire cérébral — prise en charge précoce (alerte, phase préhospitalière, phase hospitalière initiale, indications de la thrombolyse). Available from: https://www. has- sante.fr/portail/upload/docs/application/pdf/2009-07/avc_ prise_en_charge_precoce___recommandations.pdf.

8. Liberman AL, Liotta EM, Caprio FZ, Ruff I, Maas MB, Bernstein RA, et al. Do efforts to decrease door-to-needle time risk increasing stroke mimic treatment rates? Neurol Clin Pract. 2015;5(3):247-52. https:// doi.org/10.1212/CPJ.0000000000000122 
9. Hand PJ, Kwan J, Lindley RI, Dennis MS, Wardlaw JM. Distinguishing between stroke and mimic at the bedside: the brain attack study. Stroke. 2006 Mar;37(3):769-75. https://doi.org/10.1161/01. STR.0000204041.13466.4C

10. Merino JG, Luby M, Benson RT, Davis LA, Hsia AW, Latour LL, et al. Predictors of acute stroke mimics in 8187 patients referred to a stroke service. J Stroke Cerebrovasc Dis. 2013 Nov;22(8):e397-403. https://doi.org/10.1016/j.jstrokecerebrovasdis.2013.04.018

11. Libman RB, Wirkowski E, Alvir J, Rao TH. Conditions that mimic stroke in the emergency department. Implications for acute stroke trials. Arch Neurol. 1995 Nov;52(11):1119-22. https://doi.org/10.1001/ archneur.1995.00540350113023

12. Zinkstok SM, Engelter ST, Gensicke H, Lyrer PA, Ringleb PA, Artto $\checkmark$, et al. Safety of thrombolysis in stroke mimics: results from a multicenter cohort study. Stroke. 2013 Apr;44(4):1080-4. https://doi. org/10.1161/STROKEAHA.111.000126

13. Winkler DT, Fluri F, Fuhr P, Wetzel SG, Lyrer PA, Ruegg S, et al. Thrombolysis in Stroke Mimics Frequency, Clinical Characteristics, and Outcome. Stroke. 2009;40(4):1522-5. https://doi.org/10.1161/ STROKEAHA.108.530352

14. Kostulas N, Larsson M, Kall T, von Euler M, Nathanson D. Safety of thrombolysis in stroke mimics: an observational cohort study from an urban teaching hospital in Sweden. BMJ Open. 2017;7(10):e016311. https://doi.org/10.1136/bmjopen-2017-016311

15. Chen Y, Bogosavljevic V, Leys D, Jovanovic D, Beslac-Bumbasirevic L, Lucas C. Intravenous thrombolytic therapy in patients with stroke mimics: baseline characteristics and safety profile. Eur J Neurol. 2011 Oct;18(10):1246-50. https://doi.org/10.1111/j.14681331.2011.03367.x

16. Chang J, Teleb M, Yang JP, Alderazi YJ, Chapple K, Frey JL, et al. A model to prevent fibrinolysis in patients with stroke mimics. J Stroke Cerebrovasc Dis. 2012 Nov;21(8):839-43. https://doi.org/10.1016/j. jstrokecerebrovasdis.2011.04.018

17. Chernyshev OY, Martin-Schild S, Albright KC, Barreto A, Misra V, Acosta I, et al. Safety of tPA in stroke mimics and neuroimagingnegative cerebral ischemia. Neurology. 2010;74(17):1340-5. https:// doi.org/10.1212/WNL.0b013e3181dad5a6

18. Förster A, Griebe M, Wolf ME, Szabo K, Hennerici MG, Kern R. How to identify stroke mimics in patients eligible for intravenous thrombolysis? J Neurol. 2012 Jul;259(7):1347-53. https://doi. org/10.1007/s00415-011-6354-9

19. Mouthon-Reignier C, Bonnaud I, Gaudron M, Vannier-Bernard S, Bodin JF, Cottier JP, et al. Impact of a direct-admission stroke pathway on delays of admission, care, and rates of intravenous thrombolysis. Rev Neurol (Paris). 2016 Dec;172(12):756-60. https:// doi.org/10.1016/j.neurol.2016.10.008
20. Avellaneda-Gómez C, Rodríguez Campello A, Giralt Steinhauer E, et al. Description of stroke mimics after complete neurovascular assessment. Neurologia. 2019 Jan-Feb;34(1):7-13. https://doi. org/10.1016/j.nrl.2016.10.006

21. Dawson A, Cloud GC, Pereira AC, Moynihan BJ. Stroke mimic diagnoses presenting to a hyperacute stroke unit. Clin Med (Lond). 2016 Oct;16(5):423-6. https://doi.org/10.7861/ clinmedicine.16-5-423

22. Quenardelle V, Lauer-Ober V, Zinchenko I, Bataillard M, Rouyer O, Beaujeux R, et al. Stroke mimics in a stroke care pathway based on MRI screening. Cerebrovasc Dis 2016;42(2-3):205-12. https://doi. org/10.1159/000445956

23. Nguyen PL, Chang JJ. Stroke mimics and acute stroke evaluation: clinical differentiation and complications after intravenous tissue plasminogen activator. J Emerg Med. 2015 Aug;49(2):244-52. https:// doi.org/10.1016/j.jemermed.2014.12.072

24. Ali SF, Viswanathan A, Singhal AB, Rost NS, Forducey PG, Davis LW, et al. The TeleStroke Mimic (TM)-Score: A prediction rule for identifying stroke mimics evaluated in a telestroke network. J Am Heart Assoc. 2014 Jun;3(3):e000838. https://doi.org/10.1161/ JAHA.114.000838

25. Khan NI, Chaku S, Goehl C, Endris L, Mueller-Luckey G, Siddiqui FM. Novel algorithm to help identify stroke mimics. J Stroke Cerebrovasc Dis. 2018 Mar;27(3):703-708. https://doi.org/10.1016/j. jstrokecerebrovasdis.2017.09.067

26. Hosseininezhad M, Sohrabnejad R. Stroke mimics in patients with clinical signs of stroke. Caspian J Intern Med. 2017;8(3):213-6. https://doi.org/10.22088/cjim.8.3.213

27. Danière F, Edjlali-Goujon M, Mellerio C, Turc G, Naggara O, Tselikas L, et al. MR screening of candidates for thrombolysis: How to identify stroke mimics?. J Neuroradiol. 2014 Dec;41(5):283-95. https://doi. org/10.1016/j.neurad.2014.05.008

28. Vilela P. Acute stroke differential diagnosis: Stroke mimics. Eur J Radiol. 2017 Nov;96:133-44. https://doi.org/10.1016/j. ejrad.2017.05.008

29. Tobin WO, Hentz JG, Bobrow BJ, Demaerschalk BM. Identification of stroke mimics in the emergency department setting. J Brain Dis. 2009;1:19-22. https://doi.org/10.4137/jcnsd.s2280

30. Valle J, Lopera E, Guillán M, Muñoz MC, Sánchez A, Hernández Y. Imitadores del ictus: un reto para el médico de urgencias. Anales Sis San Navarra. 2014 Jan/Abr;37(1):117-28. http://dx.doi.org/10.4321/ S1137-66272014000100013

31. Faiz KW, Labberton AS, Thommessen B, Rønning OM, Dahl FA, Barra $M$. The burden of stroke mimics: present and future projections. J Stroke Cerebrovasc Dis. 2018 May;27(5):1288-95. https://doi. org/10.1016/j.jstrokecerebrovasdis.2017.12.011 